\title{
Parity differences in the behavior of transition dairy cows
}

\author{
H. W. Neave, J. Lomb, M. A. G. von Keyserlingk, A. Behnam-Shabahang, and D. M. Weary ${ }^{1}$ \\ Animal Welfare Program, Faculty of Land and Food Systems, University of British Columbia, 2357 Mall, Vancouver, BC, V6T 1Z4, Canada
}

\begin{abstract}
During the transition period, around the time of calving, cows experience a suite of stressful events, including regrouping, diet changes, parturition, and the onset of lactation. These changes may be more difficult for primiparous cows that have not had these experiences previously. The objective of this study was to compare feeding, social, exploratory, and lying behaviors of primiparous and multiparous cows during the transition period. Thirty-eight healthy primiparous and 62 healthy multiparous dairy cows were housed in mixed-parity groups of 20 with access to 12 electronic feed bins from 3 wk before to 3 wk after calving. Primiparous cows had lower dry matter intake, spent more time feeding, ate more slowly, visited the feeder more frequently, and explored their feeding environment more compared with multiparous cows. Primiparous cows also lay down more frequently, but for shorter periods, such that total lying time did not differ between these parity classes. Primiparous cows were also replaced at the feeder more often than multiparous cows. These results show how the behavior of primiparous and multiparous cows differs during the transition period, and support the idea that primiparous cows may benefit from different management during this period.
\end{abstract}

Key words: heifer, development, social competition, animal welfare, mixing

\section{INTRODUCTION}

During the transition period, from 3 wk before to 3 wk after calving, cows undergo physiological changes associated with the birth of a calf and initiation of lactation (Grummer, 1995). Cows also typically experience multiple regroupings and diet changes at this time (Cook and Nordlund, 2004). Perhaps in part due to these multiple stressors, many animals become ill over the transition period; LeBlanc et al. (2006) estimated that $75 \%$ of illness events occur within 3 wk of calving.

Received February 3, 2016.

Accepted September 19, 2016.

${ }^{1}$ Corresponding author: dan.weary@ubc.ca
Whereas all cows face these changes, one might expect that some changes will be especially disruptive for primiparous animals. Authors of previous studies have found that primiparous cows are more likely to experience negative health outcomes during transition compared with multiparous cows. For example, primiparous cows are more susceptible to dystocia and mastitis (Matthews et al., 1992). Higher rates of disease for primiparous cows may be due to nutritional deficiencies (Heinrichs et al., 2009) and a depressed immune response (McDougall et al., 2009) associated with stressors, including competition from older animals (Parker et al., 2007).

Several studies have used changes in behavior to identify animals that are ill or at risk of becoming ill during the transition period (reviewed by Proudfoot et al., 2012; Sepúlveda-Varas et al., 2013). Changes in feeding and social behaviors have been documented for several diseases in dairy cattle, including metritis (Urton et al., 2005; Hammon et al., 2006; Huzzey et al., 2007), ketosis (González et al., 2008; Goldhawk et al., 2009), hypocalcemia (Jawor et al., 2012), and lameness (Proudfoot et al., 2010; Calderon and Cook, 2011). Identifying behavioral changes related to illness requires an understanding of how healthy cows behave.

Few studies have measured differences in feeding behaviors between healthy primiparous and multiparous dairy cows during peak lactation, including differences in feed intake, feeding rate, meal frequency (Azizi et al., 2009), feeding time, and meal size (Beauchemin et al., 2002). Many studies include parity as an effect in statistical models or consider primiparous and multiparous cows as separate data sets; yet, to our knowledge, no study has compared feeding and social behaviors of primiparous and multiparous cows over the transition period.

Feeding behavior studies commonly focus on measures of feed intake, feeding time, and meal characteristics, but another important aspect of feeding behavior is exploratory sampling of the feed bunk. Cows perform exploratory sampling of feeding sites to assess the quality of feed available (Provenza, 1995). In a freestall barn, this behavior involves the animal moving between feeding locations along the feed bunk that ultimately increases time spent not feeding and may 
increase competitive interactions with other animals in the feeding area. Exploratory feed sampling has been reported in growing heifers (Huzzey et al., 2014), but little is known about this behavior in mature cows, how it changes over the transition period, and how it varies with parity.

Limited research exists on the differences in lying behavior of primiparous and multiparous cows during the transition period. Before calving, primiparous Jersey cows housed in a freestall barn spent less time lying down than multiparous cows, with a greater number of shorter duration lying bouts per day (Lobeck-Luchterhand et al., 2015). Grazing primiparous Holstein cows showed similar behaviors compared with multiparous cows in the 3 wk after calving, with shorter lying times that were divided into more numerous but shorter bouts (Sepúlveda-Varas et al., 2014). However, lying behaviors are influenced by housing system (Krohn and Munksgaard, 1993; Navarro et al., 2013), and it is unclear how primiparous and multiparous Holstein cows differ in lying behavior during the weeks around calving when housed in a freestall barn.

Primiparous cows are typically smaller and produce less milk than multiparous cows (Beauchemin and Rode, 1994), and these factors may affect behavior even within parity. To date, no study has examined how the behaviors described above are affected by the combined effect of parity (including the correlated differences in size and milk production) as well as examined the residual effects of parity after accounting for variation due to these other factors.

The aim of this study was to describe feeding, social, and exploratory behaviors at the feed bunk, as well as lying behaviors of healthy transition primiparous and multiparous cows. We hypothesized that healthy primiparous dairy cows would show reduced DMI, feeding time, and feeding visits, increased competitive interactions at the feed bunk, less exploratory behavior, and reduced lying times in comparison to multiparous cows. We tested parity differences using a simple model that included just the effect of parity, as well as using a more complex model that first accounted for the effects of BW and milk production and then considered any residual variation due to parity.

\section{MATERIALS AND METHODS}

\section{Animals, Housing, and Diet}

Data were collected from July 2013 to November 2014 at the University of British Columbia (UBC) Dairy Education and Research Center in Agassiz, British Columbia, Canada. All procedures were approved by the UBC Animal Ethics Committee (Protocol A14-0040).
Throughout this paper, we refer to primiparous cows as those animals that are experiencing the transition period (both pre- and postpartum) for the first time. During the study period, 337 Holstein dairy cows, including 105 primiparous cows and 232 multiparous cows [average parity $=1.8 \pm 1.9$ (mean \pm SD); range $=0-8$ lactations], calved. Cows were housed together in mixed-parity groups of 20 (proportion of primiparous to multiparous cows $=0.32 \pm 0.15$; range $=0.08-0.68$ ) beginning 3 wk before their predicted calving date. Pens were equipped with 12 Insentec (Insentec, Marknesse, the Netherlands) feed bins, 2 Insentec water bins, and 24 freestalls with pasture mats (Pasture Mat, Promat Inc., Woodstock, Ontario, Canada) covered with 5 $\mathrm{cm}$ of sand bedding. Upon imminent signs of calving (i.e., udder enlargement, milk letdown, relaxation of tail ligament) cows were moved from the prepartum pen to a maternity pen holding a maximum of 2 cows and equipped with 6 Insentec feed bins and 1 Insentec water bin. Within $24 \mathrm{~h}$ of calving cows were moved to a postpartum pen (same setup as the prepartum pen), where they remained until 3 wh postpartum. Cows were weighed over 2 consecutive days during the prepartum $(\mathrm{d}-21$ to -1$)$ and postpartum (d 20 to 23 ) periods and an average BW for each period was calculated.

Postpartum cows were milked twice per day at approximately 0700 and $1700 \mathrm{~h}$. Both pre- and postpartum cows were fed a TMR twice daily at approximately 0800 and $1600 \mathrm{~h}$. Both diets were formulated according to the NRC (2001) guidelines to meet or exceed the requirements of a $620-\mathrm{kg}$ Holstein cow producing 40 $\mathrm{kg} / \mathrm{d}$ of $3.5 \%$ FCM. The prepartum cow TMR included $32 \%$ corn silage, $37 \%$ alfalfa hay, $18 \%$ rye grass straw, and $13 \%$ concentrate $(\mathrm{DM}=52.4 \pm 4.7 \%, \mathrm{CP}=14.3$ $\pm 0.34 \% \mathrm{DM}, \mathrm{ADF}=34.6 \pm 0.60 \% \mathrm{DM}, \mathrm{NDF}=46.5$ $\pm 0.17 \% \mathrm{DM}$, and $\left.\mathrm{NE}_{\mathrm{L}}=1.39 \pm 0.0071 \mathrm{Mcal} / \mathrm{kg}\right)$. The postpartum cow TMR included $26 \%$ corn silage, $13 \%$ grass silage, $7 \%$ alfalfa hay, $4 \%$ grass hay, and $50 \%$ grain concentrate mash $(\mathrm{DM}=50.35 \pm 2.5 \%, \mathrm{CP}=$ $18.3 \pm 0.58 \% \mathrm{DM}, \mathrm{ADF}=18.1 \pm 0.71 \% \mathrm{DM}, \mathrm{NDF}=$ $28.5 \pm 1.2 \% \mathrm{DM}$, and $\left.\mathrm{NE}_{\mathrm{L}}=1.72 \pm 0.014 \mathrm{Mcal} / \mathrm{kg}\right)$.

Because 30 to $50 \%$ of dairy cows become ill over the transition period (LeBlanc, 2010), we followed stringent health assessment methods to reduce the risk that any ill animals would be part of the study. All animals in the herd were subjected to routine, detailed health assessments by trained farm staff to identify healthy cows with a much higher degree of certainty than would be common on a commercial farm. Clinical cases of mastitis, ketosis, downer cow syndrome, and displaced abomasum were recorded using Dairy Comp 305 (Valley Agricultural Software, Tulare, CA). Mastitis was detected by inspection of the udders for inflamed or hard udder or quarters and clots in the milk. Screen- 
ing occurred twice per day during the morning and afternoon milking. Ketosis was diagnosed using several symptoms, including reduced intake and decreased milk yield, and was confirmed using a milk BHB test strip (KetoTest, Elanco Animal Health, Nagoya, Japan). A cow was considered to have downer cow syndrome if she was recumbent and unable to stand, either before or after treatment. Displaced abomasum cases were identified initially by farm staff and confirmed by the herd veterinarian. Screening for metritis was performed every $3 \mathrm{~d}$ after calving according to Huzzey et al. (2007). Body temperatures were taken daily using a digital thermometer (Nexcare Rapid Digital Thermometer, 3M, St. Paul, MN) following morning milking. Blood samples were drawn from the coccygeal vessel into $10-\mathrm{mL}$ sterile tubes coated with sodium heparin (BD Vacutainer, Franklin Lakes, NJ) between d -8 and -1 , on d 0 , and then every $3 \mathrm{~d}$ until d 21 after calving. Plasma was collected via centrifugation $(2,800 \times g$ for 15 min at $4^{\circ} \mathrm{C}$ ) and stored at $-20^{\circ} \mathrm{C}$ until processing at the University of Guelph Animal Health Laboratory (Guelph, Ontario, Canada). Blood samples from d 3, 6, and 12 from all cows were analyzed for concentrations of plasma BHB.

A total of 203 cows were excluded from the final analysis due to postpartum illnesses, including cows with mastitis $(\mathrm{n}=9)$, metritis $(\mathrm{n}=74)$, ketosis $(\mathrm{n}=$ $2)$, downer cow syndrome $(\mathrm{n}=3)$, displaced abomasum $(\mathrm{n}=6)$, lameness (gait score $>3 ; \mathrm{n}=10$ ), dystocia ( $\mathrm{n}$ $=13)$, cows that received 2 or more drenches $(\mathrm{n}=9)$, cows that had more than $2 \mathrm{~d}$ of fever $(\mathrm{n}=12)$, or more than 1 of any of the above cases $(\mathrm{n}=65)$. An additional 19 cows were excluded from the study due to incomplete electronic data prepartum (due to early calving) or postpartum (due to space constraints requiring that the animal be moved from the test pen). The remaining cows were then screened for high BHB concentrations that have been used to classify cows as subclinically ketotic (Työppönen and Kauppinen, 1980); heightened BHB concentrations are also considered a risk factor for metritis and retained placenta (Dubuc et al., 2010; Leblanc, 2010; Ospina et al., 2010). Thus, we excluded an additional 15 cows that had at least 1 sample above 1.2 $\mathrm{mmol} / \mathrm{L}$ of BHB (LeBlanc, 2010) from the study. Cows were considered healthy and included in our analysis if, during the $21 \mathrm{~d}$ after calving, they were free of clinical disorders and exhibited no more than 2 consecutive days of fever (rectal temperature $\geq 39.5^{\circ} \mathrm{C}$ ).

Average BW for primiparous cows for pre- and postpartum periods was (mean $\pm \mathrm{SD}$ ) $627.1 \pm 46.1$ and $568.2 \pm 47.0 \mathrm{~kg}$, respectively. Average BW for multiparous cows for pre- and postpartum periods was $774.2 \pm 66.6$ and $674.3 \pm 54.7 \mathrm{~kg}$, respectively. Average daily milk production over the first $21 \mathrm{~d}$ postpartum for primiparous and multiparous cows was $23.9 \pm 4.1$ and $33.9 \pm 4.9 \mathrm{~kg} / \mathrm{d}$, respectively.

\section{Feeding and Social Behavior Measures}

The Insentec feed bins were used to monitor feeding, exploratory, and social behaviors. Each cow was fitted with an electronic ear tag (High Performance ISO Half Duplex Electronic ID Tag by Allflex Inc. St. Hyacinthe, Quebec, Canada), which the Insentec System used to allow and record individual access to each of the feed and water bins [see Chapinal et al. (2007) for a full description of this system]. All animals had access to all 12 feed bins in their pen before and after calving. Measures of feeding behavior included feeding rate (calculated as DMI in $\mathrm{g} / \mathrm{min}$ ), number of meals per day, and number of visits to the feed bins. Meals were classified as being separated by 16.7-min intervals before calving and by 20.1-min intervals after calving, as described by Proudfoot et al. (2009). The daily number of meals was calculated by summing the number of intervals between meals and adding one. Dry matter intake was also calculated as a percentage of BW, but these results did not differ from the unadjusted DMI values; therefore, we report the unadjusted DMI values. Exploratory behavior was estimated using the number of different feed bins accessed within a meal.

Social behaviors were recorded as the number of daily competitive interactions using the concept of replacements. A replacement was recorded when 1 cow (actor) replaced another cow (reactor) by physically making contact and taking her place at a feed bin within an interval of under $26 \mathrm{~s}$ of her departure from this bin. This measure of electronically identified replacements using this criterion is highly correlated with the number of displacements measured using the gold standard of video analysis (Huzzey et al., 2014). Because a cow must be present at the feed bin for it to be replaced, we report both actor replacements (the number of times a cow was the actor in displacing a cow from the feed bin) and reactor replacements (the number of times a cow was the reactor or was displaced), expressed as a ratio of the total daily number of feeder visits (number of replacements/number of feeder visits) and as a ratio of the total time spent feeding (number of replacements/ feeding time).

\section{Lying Behavior Measures}

Lying behaviors were recorded using electronic data loggers (HOBO Pendant G Acceleration Data Logger, Onset Computer Corporation, Pocasset, MA). Loggers were attached to the medial side of 1 hind leg of the 
cow using Vet Wrap (Co-Flex, Andover Coated Products Inc., Salisbury, MA), and each week the logger was changed to alternating legs. The loggers were set to record the $\mathrm{g}$-forces of the $\mathrm{y}$ - and $\mathrm{z}$-axis at 1-min intervals. Lying data were processed using the cut point reported by Ledgerwood et al. (2010) and an adjusted version of the SAS algorithm developed by UBC Animal Welfare Program (2013), as described in Zobel et al. (2015). Measures of lying behavior included total time per day, number of bouts per day, and bout durations.

\section{Statistical Analyses}

Following the exclusion criteria described above, the final analysis included 38 healthy primiparous and 62 healthy multiparous cows. All statistical analyses were conducted in SAS (Version 9.4; SAS Institute Inc., Cary, NC). Feeding and social behaviors for each day of the transition period from $14 \mathrm{~d}$ before calving until 21 $\mathrm{d}$ after calving were screened using the UNIVARIATE procedure in SAS and inspection of probability distribution plots. Extreme outliers (3 interquartile ranges beyond the first or third quartile of the data set) were likely the result of feed bin malfunctioning and were removed. Data were summarized into 5 periods based on week relative to calving: wk $-2(\mathrm{~d}-14$ to -8$)$, wk -1 (d -7 to -1 ), wk 0 (calving; $\mathrm{d}-1$ to $\mathrm{d} 1$ ) wk 1 (d 2 to 7 ), and wk 2 (d 8 to 14 ).

For accurate estimation of lying behavior, at least $3 \mathrm{~d}$ of consecutive observations are needed (Ito et al., 2009). Thus, for this analysis, only cows that had at least 3 consecutive days of data for each period were included, resulting in 18 primiparous and 33 multiparous cows in the final analysis. Data loss was due to malfunction of the loggers or logger change during 1 of the $3 \mathrm{~d}$ in wk 0. PROC UNIVARIATE was used to evaluate model fit. Data were summarized into weekly periods as described above.

Prior to analysis, we performed a power analysis based upon the means and standard deviations reported for feed intake, visits, and feeding rate in Proudfoot et al. (2009). This analysis indicated a minimum of 23 animals per group. Given a 2:1 multiparous-to-primiparous ratio of cow availability, we used 23 primiparous and 46 multiparous cows in our power analysis, with an $\alpha$ of 0.05 and power of 0.8. Differences in feeding behavior (DMI, feeding time, visits, feeding rate, meals), exploratory behavior (number of bins accessed per meal), social behavior (actor and reactor replacements), and lying behavior (total time, number of bouts, and average bout duration) between primiparous and multiparous cows were analyzed using the MIXED procedure in SAS, where weekly period was a repeated measure and cow was the experimental unit. We took 2 statistical approaches to test these behavioral differences in a Type 1 test of fixed effects model. The first model included only parity, weekly period, and the interaction of parity and period as fixed effects. The second model included as covariates BW and milk production in the first $21 \mathrm{~d}$ after calving, in addition to the fixed effects of parity, weekly period, and the interaction of parity and period. In preliminary testing maximum daily temperature was also included as a covariate, but this was never significant and was dropped from the final analysis. Results are reported as least squares means and standard error, and parity $\times$ period interactions are reported where significant. $F$ values are specified for significant variables in the format $F_{\mathrm{df}}$.

\section{RESULTS}

\section{Feeding Behaviors}

In the simple model that assessed the effects of parity and period, primiparous cows had lower DMI than multiparous cows $\left(F_{1,98}=65.43 ; P<0.001\right)$, especially in the weeks after calving (Figure $1 \mathrm{~A}$; period $\times$ parity interaction $\left.F_{5,475}=9.98 ; P<0.001\right)$. After controlling for the effect of BW and milk production, the effect of parity $\left(F_{1,95}=7.80 ; P<0.01\right)$ and parity $\times$ period interaction effects remained $\left(F_{5,470}=9.43 ; P<0.001\right)$, driven by multiparous cows eating approximately 2 $\mathrm{kg} / \mathrm{d}$ more than primiparous cows in the weeks after calving (Table 1). When DMI was expressed as a percentage of BW, we observed no effect of parity or parity $\times$ period interaction in either model.

According to the simple model, primiparous cows had lower feeding rates $\left(F_{1,98}=32.09 ; P<0.001\right.$; Figure 1B) and a greater number of feed bin visits $\left(F_{1,98}\right.$ $=20.25 ; P<0.001 ;$ Figure $1 \mathrm{C})$ compared with multiparous cows, but parity differences disappeared after controlling for differences in BW and milk production in the more complex model (Table 1). In the simple model we found a parity $\times$ period interaction in time spent feeding $\left(F_{5,475}=11.11 ; P<0.001\right)$, associated with primiparous cows spending more time feeding in the prepartum period compared with multiparous cows (Figure 1D). After controlling for the effect of BW and milk production, we noted an effect of parity $\left(F_{1,95}=\right.$ 7.84; $P<0.01)$ and a parity $\times$ period interaction $\left(F_{5,470}\right.$ $=10.95 ; P<0.001$; Table 1 ).

No difference was observed in number of meals between primiparous and multiparous cows for either the simple (Figure 1E) or complex model (Table 1). In the simple model, primiparous cows visited more bins per meal $\left(F_{1,98}=3.83 ; P=0.05 ;\right.$ Figure $\left.1 \mathrm{~F}\right)$. This parity dif- 
ference was reversed in the more complex model; after controlling for BW and milk production, primiparous cows visited fewer bins per meal than did multiparous cows $\left(F_{1,95}=8.89 ; P<0.01 ;\right.$ Table 1$)$.
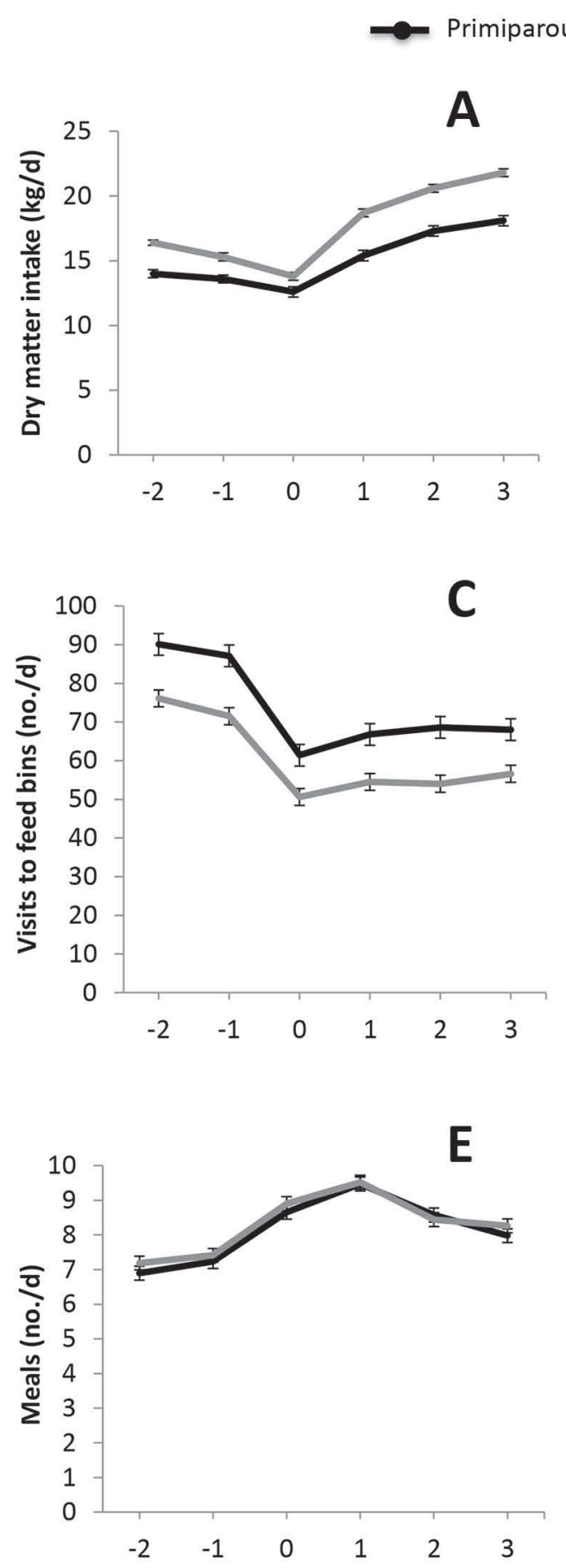

\section{Social Behaviors}

In the simple model the number of reactor replacements was greater for primiparous cows $\left(F_{1,98}=5.46 ; P\right.$

Multiparous
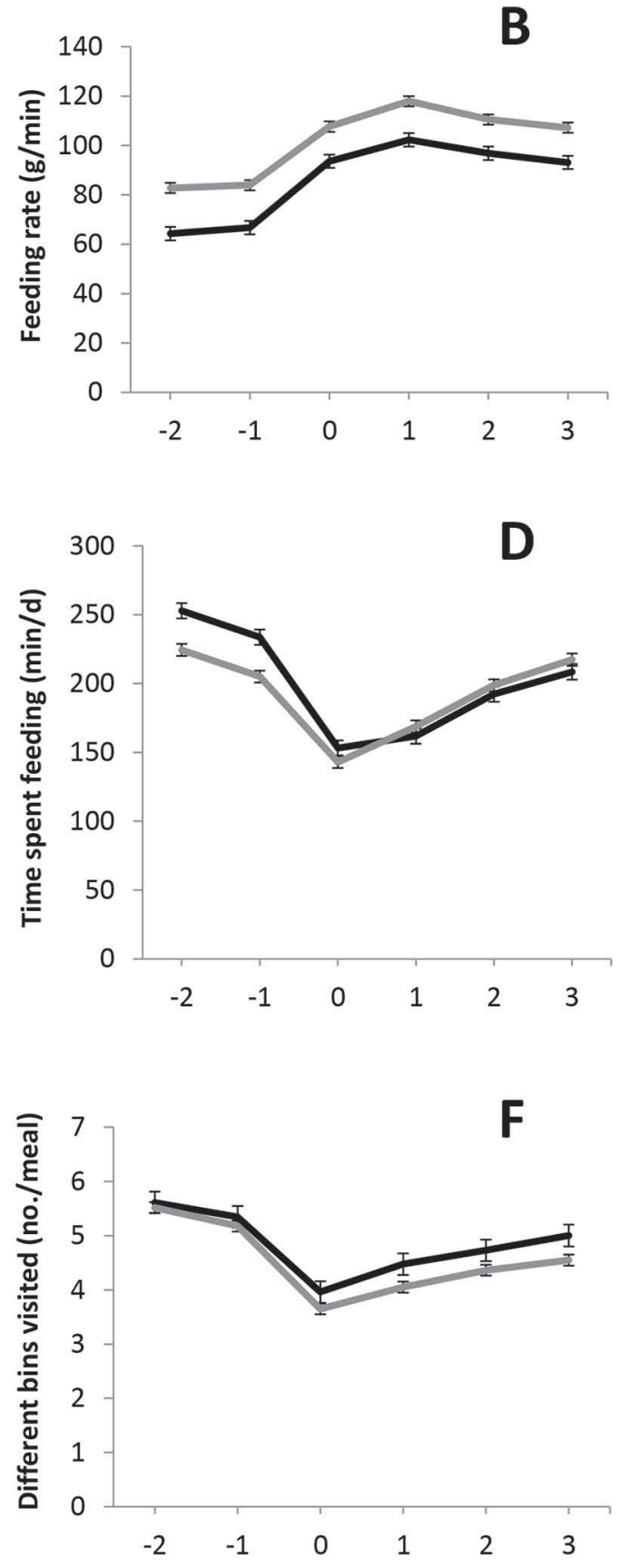

\section{Weekly period relative to calving}

Figure 1. Least squares means $( \pm \mathrm{SE})$ of $(\mathrm{A}) \mathrm{DMI}(\mathrm{kg}$ of $\mathrm{DM} / \mathrm{d}),(\mathrm{B})$ feeding rate $(\mathrm{g} / \mathrm{min})$, (C) visits to the feed bin (no./d), (D) feeding time (min/d), (E) meals (no./d), and (F) different bins visited (no./meal) for primiparous (n=38) and multiparous (n =62) Holstein dairy cows during each experimental period relative to calving. 
PARITY DIFFERENCES IN TRANSITION DAIRY COWS

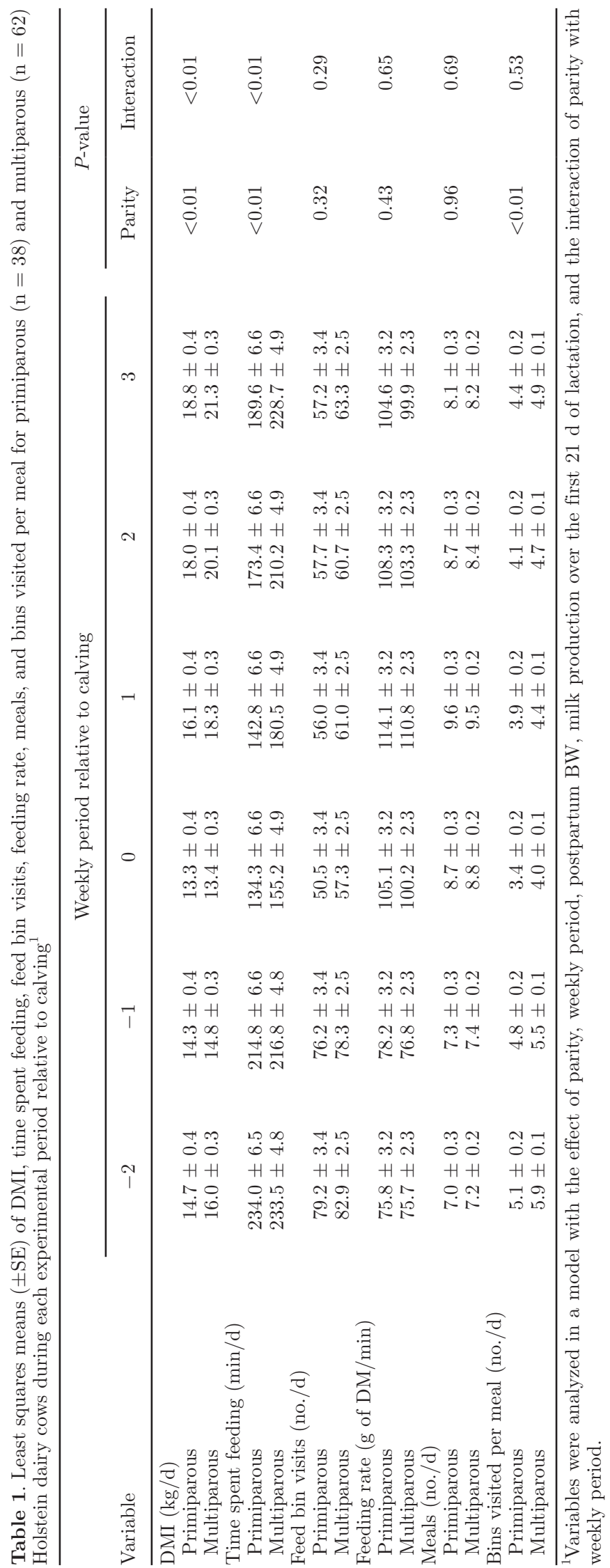




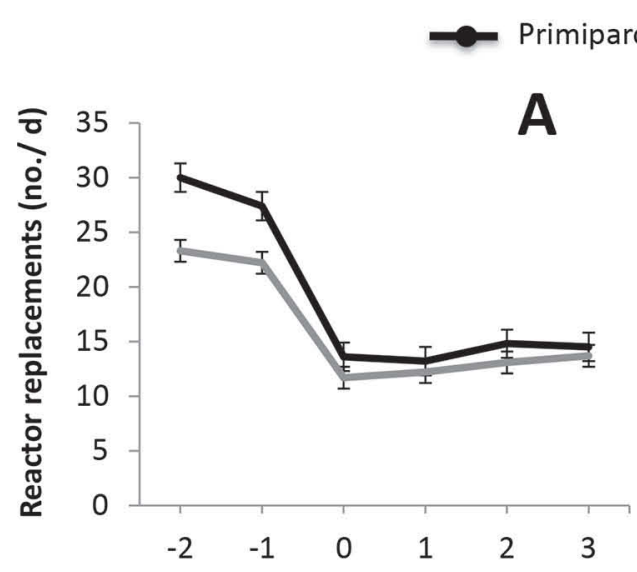

Multiparous
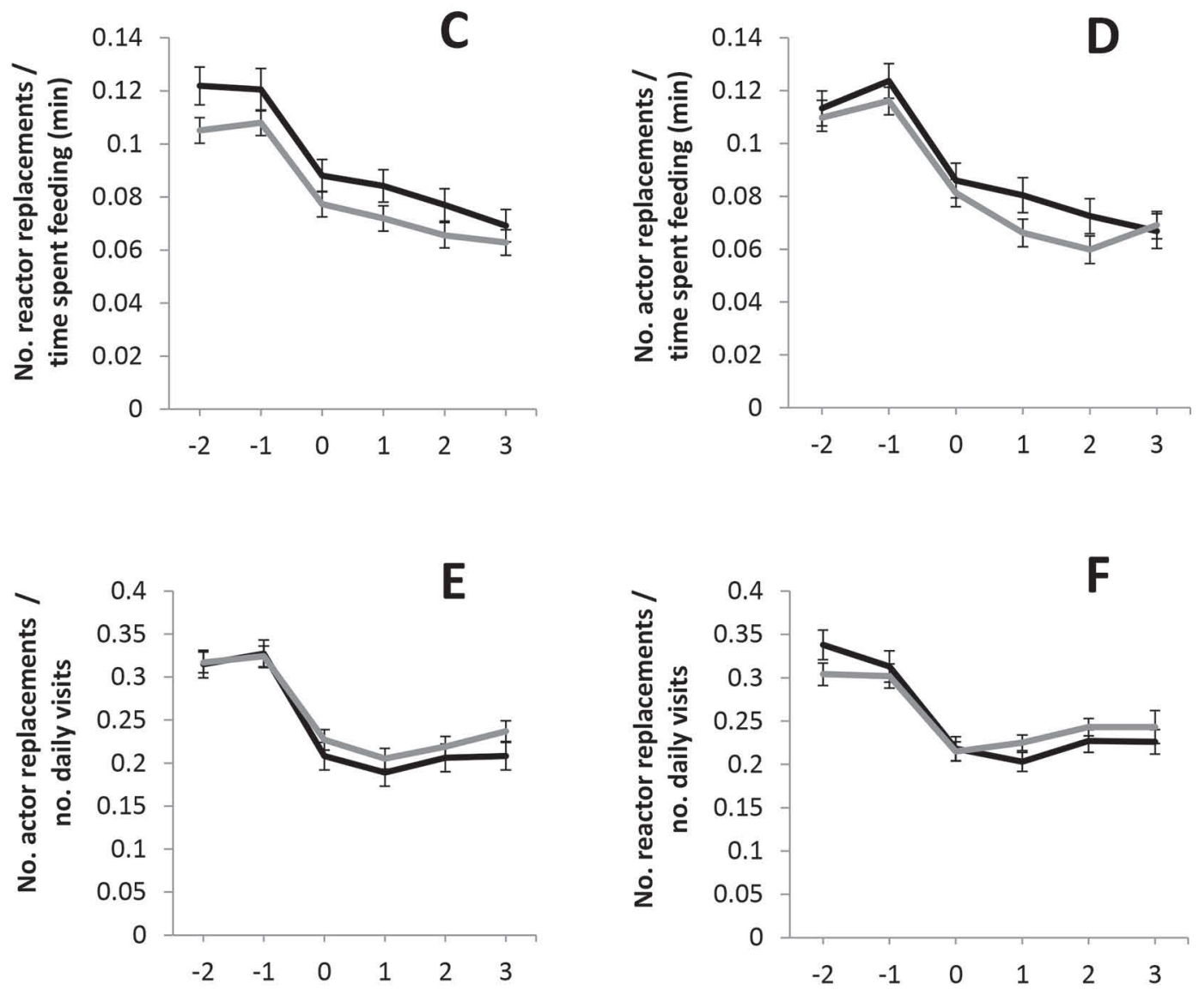

Weekly period relative to calving

Figure 2. Least squares means $( \pm \mathrm{SE})$ of $(\mathrm{A})$ reactor replacements (no./d), (B) actor replacements (no./d), (C) reactor replacements (no.) per time spent feeding ( $\mathrm{min})$, (D) actor replacements (no.) per time spent feeding (min), (E) actor replacements (no.) per visit, and (F) reactor replacements (no.) per visit for primiparous $(\mathrm{n}=38)$ and multiparous $(\mathrm{n}=62)$ Holstein dairy cows during each experimental period relative to calving.

$<0.05$ ), especially in the weeks before calving (parity $\times$ period interaction $F_{5,475}=2.96 ; P<0.05$; Figure $2 \mathrm{~A})$. After controlling for the effect of $\mathrm{BW}$ and milk production a similar parity $\times$ period interaction remained $\left(F_{5,470}=2.95 ; P<0.05 ;\right.$ Table 2$)$. The total number of actor replacements did not differ between 
PARITY DIFFERENCES IN TRANSITION DAIRY COWS

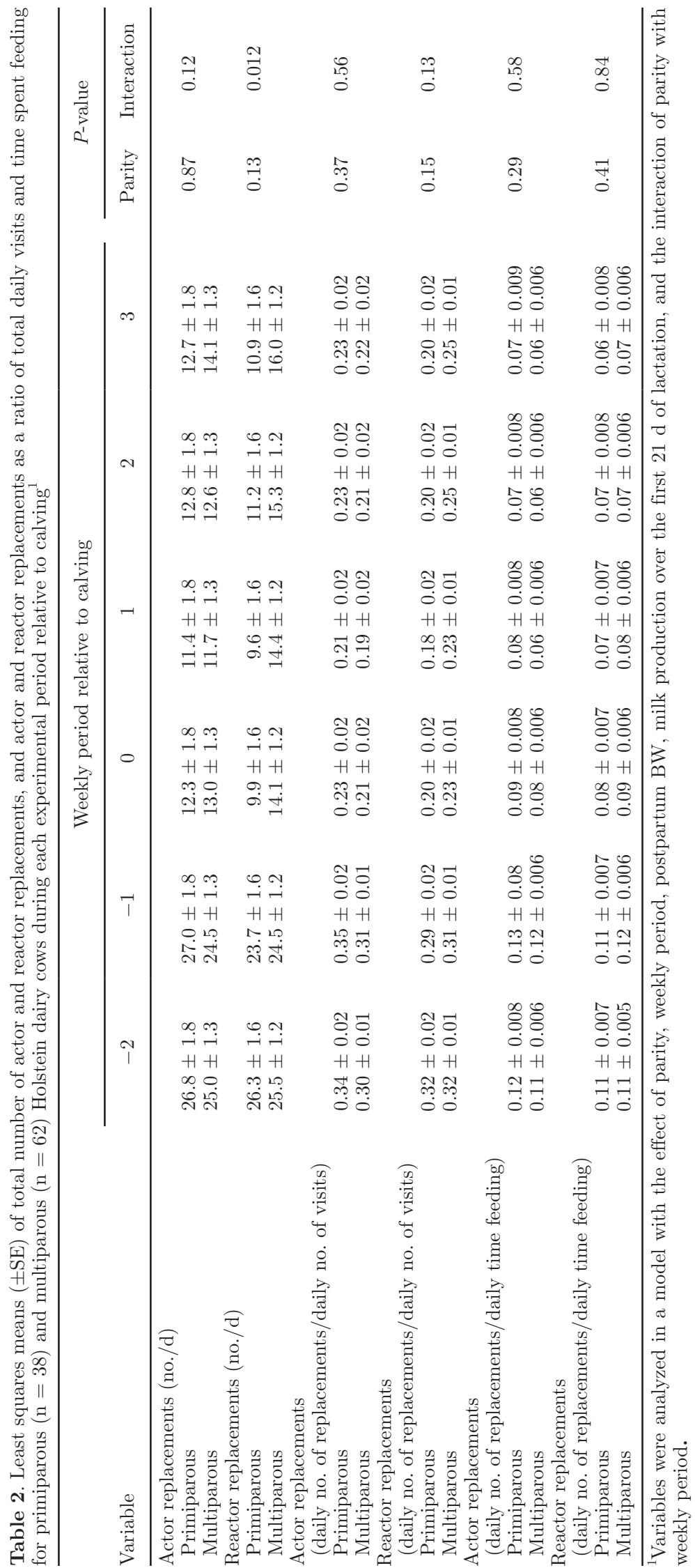


primiparous and multiparous cows in either model (Figure 2B; Table 2).

Reactor replacements as a ratio of feeding time was greater in primiparous cows $\left(F_{1.98}=4.40 ; P<0.05\right.$; Figure $2 \mathrm{C}$ ), but this difference did not persist after controlling for BW and milk production (Table 2). We found no parity differences in the number of actor replacements as a ratio of the total feeding time (Figure 2D; Table 2), or in number of actor or reactor replacements as a ratio of number of daily visits (Figure 2E-F; Table 2).

\section{Lying Behaviors}

We observed a parity $\times$ period interaction for lying time in the simple model $\left(F_{5,245}=8.49 ; P<0.001\right.$; Figure $3 \mathrm{~A})$. This interaction remained in the model controlling for BW and milk production $\left(F_{5,239}=8.72\right.$; $P<0.001$; Table 3).

The number of lying bouts was greater in primiparous than multiparous cows $\left(F_{1,49}=50.03 ; P<0.001\right)$, especially in the weeks after calving (parity $\times$ period interaction $F_{5,245}=10.00 ; P<0.001$; Figure 3B). After controlling for the effect of $\mathrm{BW}$ and milk production, similar parity $\left(F_{1,47}=8.38 ; P<0.01\right)$ and parity $\times$ period interaction effects remained $\left(F_{5,239}=9.67 ; P<\right.$ 0.001 ; Table 3).

Lying bout duration was shorter in primiparous cows than multiparous cows $\left(F_{1.49}=74.43 ; P<0.001\right)$ with a parity $\times$ period interaction $\left(F_{5,245}=5.65 ; P<0.001\right)$ resulting from the primiparous cows declining over time and multiparous cows remaining constant apart from a decline at calving (Figure 3C). After controlling for BW and milk production, both parity $\left(F_{1,47}=16.92 ; P<\right.$ $0.001)$ and parity $\times$ period interaction effects remained $\left(F_{5,239}=5.40 ; P<0.001 ;\right.$ Table 3$)$.

\section{DISCUSSION}

Our study is the first to investigate behavioral differences, specifically feeding, social, exploratory, and lying behaviors, between healthy primiparous and multiparous dairy cows during the transition period, and the first to statistically control for the effects of BW and milk production on these behavioral differences. As expected, we found numerous behavioral differences between parities. Some of these differences disappeared after controlling for differences in BW and milk production, but some behavioral differences remained even after controlling for these factors.

Primiparous cows ate less than multiparous cows during the transition period. Similarly, Proudfoot et al. (2009) showed that primiparous cows ate less than multiparous cows during wk $-1,1$, and 2 after calving.
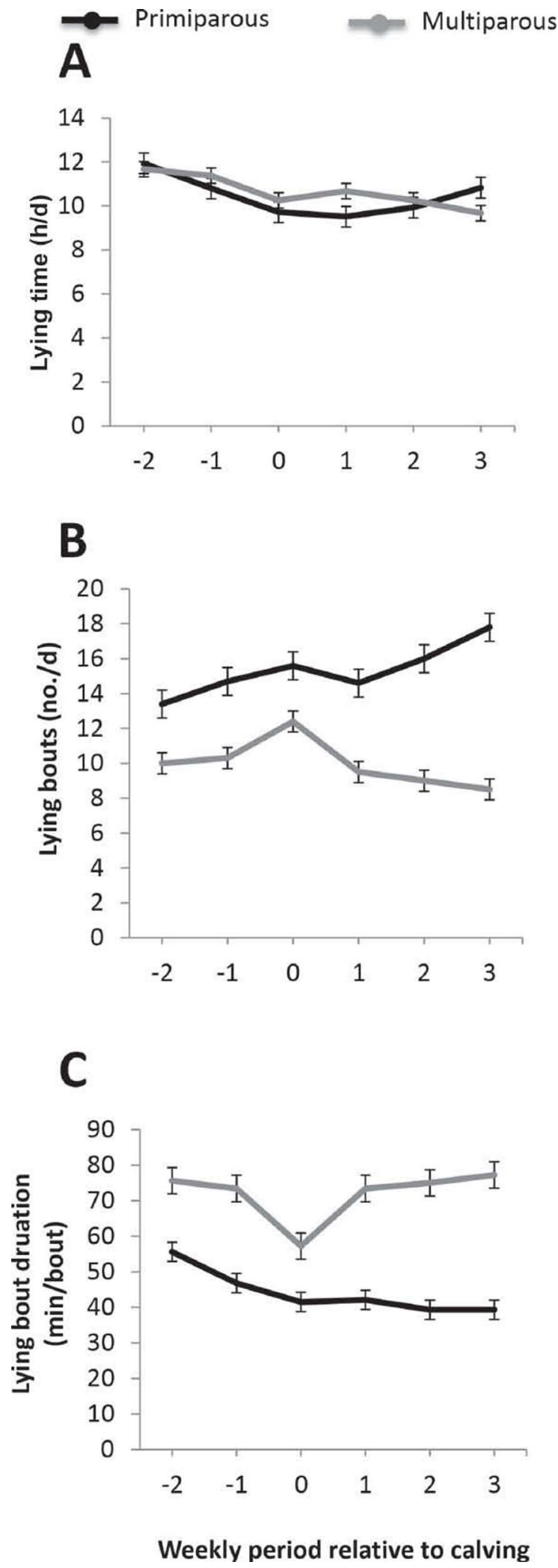

Figure 3. Least squares means $( \pm \mathrm{SE})$ of $(\mathrm{A})$ lying time $(\mathrm{h} / \mathrm{d})$, (B) lying bouts (no./d), and (C) lying bout duration ( $\mathrm{min}$ ) for primiparous $(\mathrm{n}=18)$ and multiparous $(\mathrm{n}=33)$ Holstein dairy cows during each experimental period relative to calving. 
Moore and Mao (1990) reported intakes of approximately $14 \mathrm{~kg}$ of DM for primiparous versus 15 to 16 $\mathrm{kg}$ for parities 2 to 4 during the first weeks after calving; those authors noted that BW and milk production could be important factors driving parity differences, but did not control for these factors in their study. In the current study, we found that even after controlling for BW and milk production primiparous cows ate less than the multiparous cows, with differences increasing over the postpartum period. Few studies report parity differences during transition while controlling for BW. One paper showed that first lactation animals had lower DMI in the first weeks after calving when using a predictive model that included corrections for BW and milk production (Kertz et al., 1991). Hayirli et al. (2002) reported that DMI as a percentage of BW was lower for primiparous cows during the 3 wk before calving; in the current study, we found similar intakes in primiparous and multiparous cows in the weeks before calving, perhaps because we controlled for both milk production and BW.

A novel finding of our study was that primiparous cows had a lower feeding rate and greater number of feed visits compared with multiparous cows in the simple model. These differences disappeared after controlling for BW and milk production, indicating the differences were driven by those 2 factors. One previous study reported that primiparous cows ate more slowly than multiparous cows during peak lactation (Beauchemin and Rode, 1994). Several factors can influence feeding rate, including increased motivation to feed and increased social pressure at the feed bunk (Nielsen, 1999). Multiparous cows with their larger body size (resulting in increased BW) and lactation demands require more feed, which likely contributes to increased feeding rate. Proudfoot et al. (2009) reported about half the number of visits to the feed bins for primiparous and multiparous cows compared with the current study; however, those authors had each cow assigned to a particular feed bin such that there was only competition with one other cow to access a single bin. Animals in our study competed with 19 other animals for access to any of the 12 bins available. The number of available feed bins may have contributed to the increased number of visits; this trend was reported by Nielsen et al. (1996), where pigs showed many more visits when provided 4 feeding troughs compared with only one feeding trough.

Primiparous cows spent more time feeding than multiparous cows before calving, but after controlling for $\mathrm{BW}$ and milk production the pattern changed, with primiparous cows spending less time eating after calving. To our knowledge, ours is the first report of differences in feeding time between primiparous and multiparous cows. Beauchemin et al. (2002) found that 
meal duration did not differ between parities in mid lactation despite primiparous cows consuming less per meal than their multiparous counterparts. Beauchemin et al. (2002) speculated this difference might be related to the larger bite size of the multiparous cows, which may explain parity differences in feeding rate in the current study before controlling for BW and milk production.

Our study used the number of different feed bins visited per meal as a measure of exploratory feeding behavior. Cows are known to engage in exploratory sampling, allowing them to gather information regarding the quality of feed available in their surroundings (Provenza, 1995; Bailey, 1996). For cows housed indoors, feed quality can vary over the course of the day and along the length of the feed bunk due to feed sorting (DeVries et al., 2005) or due to improper mixing of the diet. A previous study of growing heifers assessed changes in feed quality in time and space using the number of movements between feed bins (Huzzey et al., 2013). Thus, in our study, multiple unique bin visits during a meal were taken as an indicator that the cow was seeking out preferred food patches by assessing what each bin had to offer. We found that primiparous cows visited fewer bins per meal in both models. The decline in number of feed bins visited during a meal corresponded with a decline in number of replacements, suggesting cows may visit a new feed bin because they were displaced from a current bin. Future studies on exploratory feeding should consider adding barriers between feeding stations to reduce the frequency of competitive displacements.

As discussed by Nielsen (1999), feeding behavior is dependent upon the social environment in which cows are housed. A common stressor at the beginning of the transition period and again following calving is social regrouping. Social dominance relationships are established in animals that are comingled. Dominance is correlated with age of the cow, with older animals typically more dominant (Val-Laillet et al., 2008). For this reason, we had expected primiparous cows, which are typically smaller than multiparous cows, to be more likely to be replaced at the feed bins, reducing their ability to access feed. Indeed, our study showed that when examining only the effect of parity, primiparous cows were more often displaced (i.e., the reactor) in competitive interactions at the feed bin before calving. Wierenga (1990) reported that younger cows were more frequently displaced from key resources such as food or lying stalls. However, after controlling for BW, we found that the primiparous cows were replaced at the feed bins less frequently than were multiparous cows. This result suggests that primiparous cows were replaced more often mainly due to their smaller BW.
It may be that primiparous cows shift their feeding times to when occupancy of the bin is lower, and thus avoid competition with multiparous animals. Although we found no differences in reactor replacements when considered as a ratio of the total number of daily visits to the feed bin, when considered as a ratio of total time at the feeder, primiparous cows were replaced more often; this was, again, driven by $\mathrm{BW}$ and milk production characteristics. Competitive interactions at the feed bunk may be related to individual motivations to access feed resources (Val-Laillet et al., 2008). A limitation of our study is that we did not also measure displacements from the feed bins (i.e., cases in which the cow was removed from the bin but the acting cow did not replace her); replacements may be an underestimation of the social interactions between primiparous and multiparous cows. Further research is necessary to understand how competitive interactions differentially affect primiparous and multiparous animals.

Our study was the first to investigate parity differences in lying behavior of transition Holstein cows in a freestall barn. Only one previous study (Huzzey et al., 2005) described patterns for healthy Holstein cows over the complete transition period, but parity differences were not considered. We found numerically small but significant parity differences in lying time, driven by slightly shorter times in primiparous compared with multiparous cows in the week after calving. Similar results were reported for Jersey primiparous cows housed at 80 and $100 \%$ stocking density (Lobeck-Luchterhand et al., 2015). In our study, a stocking density of $83 \%$ (20 cows for 24 lying stalls) was maintained, resulting in relatively low competition at the lying stalls. However, cows have preferences for certain stalls (e.g., those with dry bedding; Fregonesi et al., 2007), so competition for the most desirable stalls may still have occurred. One of the limitations of our study is that we did not measure replacements at the lying stall and therefore cannot draw conclusions regarding lying stall competition. Sepúlveda-Varas et al. (2014) demonstrated a similar difference in lying times in postpartum animals housed on pasture, suggesting that competition for stalls is not driving the differences we report in the current study. Indeed, if competition for lying space is a major driver for shorter lying times of the younger animals, we would have expected the difference to be greatest at wk -2 , in the days after regrouping (Phillips and Rind, 2001; von Keyserlingk et al., 2008). After controlling for BW and milk production we found that the parity difference remained, suggesting factors other than BW and production are driving this difference.

Primiparous cows showed more transitions between standing and lying than multiparous cows in both models, similar to previous studies (Vasseur et al., 2012; 
Sepúlveda-Varas et al., 2014; Lobeck-Luchterhand et al., 2015). In addition, lying bout duration of primiparous cows was shorter in both models. In a study investigating changes in standing behavior of lame transition cows in a commercial freestall barn, Calderon and Cook (2011) observed that primiparous cows had a greater number of lying bouts compared with multiparous cows before calving, regardless of health status. The consistency of these findings suggests that primiparous cows show a greater number of lying bouts and shorter bout duration during transition, independent of housing system and breed. Furthermore, after controlling for BW and milk production differences in number of lying bouts and lying bout duration remained, indicating these behavioral differences are independent of these factors.

The parity differences in our study, after controlling for BW and milk production, may relate to the different experiences of these animals during the transition period. For primiparous cows, the transition period includes a series of procedures that are experienced for the first time, including diet changes, regrouping, and preparation for lactation. Some authors have suggested housing primiparous and multiparous cows separately. One study reported that first-lactation cows housed separately from multiparous cows had longer feeding times, increased feeding frequency, greater feed intake, and higher milk yield compared with first-lactation cows mixed with older cows (Krohn and Konggaard, 1979). Increased milk production in the first month postpartum in separately housed primiparous cows was also observed by Østergaard et al. (2010). Competitive interactions of separately housed nulliparous cows did not differ from multiparous cows (Lobeck-Luchterhand et al., 2015), suggesting that parity composition of the group may not reduce competition at the feed bunk. If true, this would suggest that other interventions may be more effective at reducing competitive displacements of nulli- and primiparous animals at the feed bunk, such as reduced stocking rates (Lobeck-Luchterhand et al., 2015) or using barriers at the feed bunk (DeVries and von Keyserlingk, 2006) that reduce competitive displacements for all cows.

Our study has some limitations. Our results are specific to healthy animals that were classified under strict health-assessment guidelines; most commercial farms are likely to under-diagnose these ailments, particularly metritis and ketosis. Other changes in management during the course of the experiment, such as shift and personnel changes, were not recorded systematically and were not included in the statistical analysis. We believe these changes were unlikely to systemically bias our estimate of the association of parity with the outcome measures because these changes were distributed evenly across the study and all animals enrolled in the experiment would have experienced these changes equally. However, we encourage future work to systematically record these variables to capture variation due to these factors.

Overall, the behavioral differences between healthy primiparous and multiparous cows indicate that parity should be considered in behavioral studies on transition cows. The transition period is especially important for cow health, and our results provide an important baseline for future work assessing behavioral associations with ill health before and after calving. We encourage future work on the behavior of primiparous and multiparous animals when these age classes are managed separately during the transition period.

\section{CONCLUSIONS}

This is the first study to systematically describe the association of parity with behavioral changes over the transition period. Healthy primiparous and multiparous dairy cows differed in feeding, social, and exploratory behavior at the feed bunk, as well as lying behavior during the transition period. Some of these differences disappeared after controlling for differences in BW and milk production, but other differences remained, likely due to differences in experience of these 2 parity classes. These results indicate that parity needs to be considered in analyses of transition cow behavior. More research is needed to test the effect of housing these age classes separately and of management to reduce competition on these behaviors.

\section{ACKNOWLEDGMENTS}

We thank Julie Huzzey and all the staff and students of the UBC Dairy Education and Research Centre (Agassiz, Canada) who helped with data collection in this experiment, and Joao H. Cardoso Costa (University of British Columbia) for his assistance with statistical analysis and comments in the previous version of this manuscript. We thank Boehringer Ingelheim Inc. (Guelph, Ontario) for their donation to support the various students that helped with this trial. In addition, Heather W. Neave was supported by Canada's Natural Sciences and Engineering Research Council (NSERC, Ottawa, Canada) Canada Graduate Scholarship. General funding for UBC's Animal Welfare Program comes from an NSERC Industrial Research Chair with industry contributions from the Dairy Farmers of Canada (Ottawa, ON, Canada), British Columbia Dairy Association (Burnaby, BC Canada), Westgen Endowment Fund (Milner, BC, Canada), Intervet Canada Corporation (Kirkland, QC, Canada), Novus International 
Inc. (Oakville, ON, Canada), Zoetis (Kirkland, QC, Canada), BC Cattle Industry Development Fund (Kamloops, BC, Canada), Alberta Milk (Edmonton, AB, Canada), Valacta (St. Anne-de-Bellevue, QC, Canada), and CanWest DHI (Guelph, ON, Canada).

\section{REFERENCES}

Azizi, O., O. Kaufmann, and L. Hasselmann. 2009. Relationship between feeding behavior and feed intake of dairy cows depending on their parity and milk yield. Livest. Sci. 122:156-161.

Bailey, D. W. 1996. Mechanisms that result in large herbivore grazing distribution patterns. J. Range Manage. 49:386-400.

Beauchemin, K. A., M. Maekawa, and D. A. Christensen. 2002. Effect of diet and parity on meal patterns of lactating dairy cows. Can. J. Anim. Sci. 82:215-223.

Beauchemin, K. A., and L. M. Rode. 1994. Compressed baled alfalfa hay for primiparous and multiparous dairy cows. J. Dairy Sci. 77:1003-1012.

Calderon, D. F., and N. B. Cook. 2011. The effect of lameness on the resting behavior and metabolic status of dairy cattle during the transition period in a freestall-housed dairy herd. J. Dairy Sci. 94:2883-2894.

Chapinal, N., D. M. Veira, D. M. Weary, and M. A. G. von Keyserlingk. 2007. Technical note: Validation of a system for monitoring individual feeding and drinking behavior and intake in grouphoused cattle. J. Dairy Sci. 90:5732-5736.

Cook, N. B., and K. V. Nordlund. 2004. Behavioral needs of the transition cow and considerations for special needs facility design. Vet. Clin. North Am. Food Anim. Pract. 20:495-520.

DeVries, T. J., and M. A. G. von Keyserlingk. 2006. Feed stalls affect the social and feeding behavior of lactating dairy cows. J. Dairy Sci. 89:3522-3531.

DeVries, T. J., M. A. G. von Keyserlingk, and K. A. Beauchemin. 2005. Frequency of feed delivery affects the behavior of lactating dairy cows. J. Dairy Sci. 88:3553-3562.

Dubuc, J., T. F. Duffield, K. E. Leslie, J. S. Walton, and S. J. LeBlanc. 2010. Risk factors for post-partum uterine diseases in dairy cows. J. Dairy Sci. 93:5764-5771.

Fregonesi, J. A., D. M. Veira, M. A. G. von Keyserlingk, and D. M. Weary. 2007. Effects of bedding quality on lying behavior of dairy cows. J. Dairy Sci. 90:5468-5472.

Goldhawk, C., N. Chapinal, D. M. Veira, D. M. Weary, and M. A. G. Von Keyserlingk. 2009. Prepartum feeding behavior is an early indicator of subclinical ketosis. J. Dairy Sci. 92:4971-4977.

González, L. A., B. J. Tolkamp, M. P. Coffey, A. Ferret, and I. Kyriazakis. 2008. Changes in feeding behavior as possible indicators for the automatic monitoring of health disorders in dairy cows. J. Dairy Sci. 91:1017-1028.

Grummer, R. R. 1995. Impact of changes in organic nutrient metabolism on feeding the transition dairy cow. J. Anim. Sci. 73:28202833.

Hammon, D. S., I. M. Evjen, T. R. Dhiman, J. P. Goff, and J. L. Walters. 2006. Neutrophil function and energy status in Holstein cows with uterine health disorders. Vet. Immunol. Immunopathol. 113:21-29

Hayirli, A., R. R. Grummer, E. V. Nordheim, and P. M. Crump. 2002 Animal and dietary factors affecting feed intake during the prefresh transition period in Holsteins. J. Dairy Sci. 85:3430-3443.

Heinrichs, A. J., S. Costello, and C. Jones. 2009. Control of heifer mastitis by nutrition. Vet. Microbiol. 134:172-176.

Huzzey, J. M., J. A. Fregonesi, M. A. G. von Keyserlingk, and D. M Weary. 2013. Sampling behavior of dairy cattle: Effects of variation in dietary energy density on behavior at the feed bunk. J. Dairy Sci. 96:247-256.

Huzzey, J. M., D. M. Veira, D. M. Weary, and M. A. G. von Keyserlingk. 2007. Pre-partum behavior and dry matter intake identify dairy cows at risk for metritis. J. Dairy Sci. 90:3220-3233.
Huzzey, J. M., M. A. G. von Keyserlingk, and D. M. Weary. 2005. Changes in feeding, drinking, and standing behavior of dairy cows during the transition period. J. Dairy Sci. 88:2454-2461.

Huzzey, J. M., D. M. Weary, B. Y. F. Tiau, and M. A. G. von Keyserlingk. 2014. Short communication: Automatic detection of social competition using an electronic feeding system. J. Dairy Sci. 97:2953-2958.

Ito, K., D. M. Weary, and M. A. G. von Keyserlingk. 2009. Lying behavior: Assessing within- and between-herd variation in free-stallhoused dairy cows. J. Dairy Sci. 92:4412-4420.

Jawor, P. E., J. M. Huzzey, S. J. LeBlanc, and M. A. G. von Keyserlingk. 2012. Associations of subclinical hypocalcemia at calving with milk yield, and feeding, drinking, and standing behaviors around parturition in Holstein cows. J. Dairy Sci. 95:1240-1248.

Kertz, A. F., L. F. Reutzel, and G. M. Thomson. 1991. Dry matter intake from parturition to midlactation. J. Dairy Sci. 74:2290-2295.

Krohn, C. C., and S. P. Konggaard. 1979. Effects of isolating firstlactation cows from older cows. Livest. Prod. Sci. 6:137-146.

Krohn, C. C., and L. Munksgaard. 1993. Behaviour of dairy cows kept in extensive (loose housing/pasture) or intensive (tie stall) environments II. Lying and lying-down behaviour. Appl. Anim. Behav. Sci. 37:1-16.

LeBlanc, S. 2010. Monitoring metabolic health of dairy cattle in the transition period. J. Reprod. Dev. 56:S29-S35.

LeBlanc, S., K. Lissemore, D. Kelton, T. Duffield, and K. Leslie. 2006. Major advances in disease prevention in dairy cattle. J. Dairy Sci 89:1267-1279.

Ledgerwood, D. N., C. Winckler, and C. B. Tucker. 2010. Evaluation of data loggers, sampling intervals, and editing techniques for measuring the lying behavior of dairy cattle. J. Dairy Sci. 93:5129-5139

Lobeck-Luchterhand, K. M., P. R. B. Silva, R. C. Chebel, and M. I. Endres. 2015. Effect of stocking density on social, feeding, and lying behavior of pre-partum dairy animals. J. Dairy Sci. 98:240-249.

Matthews, K. R., R. Harmon, and B. Langlois. 1992. Prevalence of Staphylococcus species during the periparturient period in primiparous and multiparous cows. J. Dairy Sci. 75:1835-1839.

McDougall, S., K. I. Parker, C. Heuer, and C. W. R. Compton. 2009. A review of prevention and control of heifer mastitis via non-antibiotic strategies. Vet. Microbiol. 134:177-185.

Moore, T. L., and I. L. Mao. 1990. Prediction of total intake of dry matter and net energy in a lactation. J. Dairy Sci. 73:1255-1262.

Navarro, G., L. E. Green, and N. Tadich. 2013. Effect of lameness and lesion specific causes of lameness on time budgets of dairy cows at pasture and when housed. Vet. J. 197:788-793.

Nielsen, B. L. 1999. On the interpretation of feeding behaviour measures and the use of feeding rate as an indicator of social constraint. Appl. Anim. Behav. Sci. 63:79-91.

Nielsen, B. L., A. B. Lawrence, and C. T. Whittemore. 1996. Feeding behaviour of growing pigs using single or multi-space feeders. Appl. Anim. Behav. Sci. 47:235-246.

NRC. 2001. Nutrient Requirements of Dairy Cattle. 7th rev. ed. Natl. Acad. Sci., Washington, DC.

Ospina, P. A., D. V. Nydam, T. Stokol, and T. R. Overton. 2010. Evaluation of nonesterified fatty acids and $\beta$-hydroxybutyrate in transition dairy cattle in the northeastern United States: Critical thresholds for prediction of clinical diseases. J. Dairy Sci. 93:546554 .

Østergaard, S., P. Thomsen, and E. Burow. 2010. Separate housing for one month after calving improves production and health in cows but not in multiparous cows. J. Dairy Sci. 93:3533-3541.

Parker, K. I., C. W. R. Compton, F. M. Anniss, A. Weir, and S. McDougall. 2007. Management of dairy heifers and its relationships with the incidence of clinical mastitis. N. Z. Vet. J. 55:208-216.

Phillips, C. J., and M. I. Rind. 2001. The effects on production and behavior of mixing uniparous and multiparous cows. J. Dairy Sci. 84:2424-2429

Proudfoot, K. L., D. M. Veira, D. M. Weary, and M. A. G. von Keyserlingk. 2009. Competition at the feed bunk changes the feeding, standing, and social behavior of transition dairy cows. J. Dairy Sci. 92:3116-3123. 
Proudfoot, K. L., D. M. Weary, and M. A. G. von Keyserlingk. 2010. Behavior during transition differs for cows diagnosed with claw horn lesions in mid lactation. J. Dairy Sci. 93:3970-3978.

Proudfoot, K. L., D. M. Weary, and M. A. G. von Keyserlingk. 2012 Linking the social environment to illness in farm animals. Appl. Anim. Behav. 138:203-215.

Provenza, F. D. 1995. Postingestive feedback as an elementary determinant of food selection and intake in ruminants. J. Range Manage. 48:2-17.

Sepúlveda-Varas, P., J. M. Huzzey, D. M. Weary, and M. A. G. von Keyserlingk. 2013. Behaviour, illness and management during the periparturient period in dairy cows. Anim. Prod. Sci. 53:988-999.

Sepúlveda-Varas, P., D. M. Weary, and M. A. G. von Keyserlingk. 2014. Lying behavior and post-partum health status in grazing dairy cows. J. Dairy Sci. 97:6334-6343.

Työppönen, J., and K. Kauppinen. 1980. The stability and automatic determination of ketone bodies in blood samples taken in field conditions. Acta Vet. Scand. 21:55-61.

UBC Animal Welfare Program. 2013. UBC Animal Welfare Program: SOP - HOBO Data Loggers. University of British Columbia, Van- couver, Canada. Accessed 8 August 2016. http://lfs-awp.sites.olt. ubc.ca/files/2013/11/SOP-HOBO-Datalogger-november-2013.pdf.

Urton, G., M. A. G. von Keyserlingk, and D. M. Weary. 2005. Feeding behavior identifies dairy cows at risk for metritis. J. Dairy Sci. 88:2843-2849

Val-Laillet, D., A. M. de Passille, J. Rushen, and M. A. G. von Keyserlingk. 2008. The concept of social dominance and the social distribution of feeding-related displacements between cows. Appl Anim. Behav. Sci. 111:158-172.

Vasseur, E., J. Rushen, D. B. Haley, and A. M. de Passillé. 2012 Sampling cows to assess lying time for on-farm animal welfare assessment. J. Dairy Sci. 95:4968-4977.

von Keyserlingk, M. A. G., D. Olenick, and D. M. Weary. 2008. Acute behavioral effects of regrouping dairy cows. J. Dairy Sci. 91:10111016.

Wierenga, H. 1990. Social dominance in dairy cattle and the influences of housing and management. Appl. Anim. Behav. Sci. 27:201-229.

Zobel, G., D. M. Weary, K. Leslie, N. Chapinal, and M. A. G. von Keyserlingk. 2015. Technical note: Validation of data loggers for recording lying behavior in dairy goats. J. Dairy Sci. 98:1082-1089. 